Z. klin. Chem. u. klin. Biochem.

7. Jg., S. $498-500$, September 1969

\title{
Eine vereinfachte Methode zur Bestimmung des freien Hydroxyprolin im Serum
}

\author{
Von D. Dabew und H. Struck \\ Aus der Biochemischen Abteilung (Leiter: Priv. Doz. Dr. H. Struck) der II. Cbirurgischen Universitätsklinik in Köln- \\ Merbeim (Direktor: Prof. Dr. W. Scbink)
}

(Eingegangen am 16. Mai 1969)

\begin{abstract}
Es wird über eine modifizierte Methode zur Bestimmung des freien Hydroxyprolin in $1 \mathrm{~m} l$ Serum bei einem maximalen Fehler von 4,5\% berichtet. Das Serum wurde durch eine kombinierte Behandlung mit absolutem Äthanol und Unterkühlung enteiweißt und von anderen äthanolunlöslichen Komponenten befreit. Der Überstand wurde in Vakuum trocken destilliert, wonach eine kolorimetrische Bestimmung des Hydroxyprolin in dem trocknen Rückstand nach StegexanN und Stalder in gewisser Modifikation exfolgte: Das dem Serum zugesetzte Hydroxyprolin wurde mit einem Fehler von 2,5\% wiedergefunden. Es konnte eine Menge von 0,4-0,5 $\mu \mathrm{g}$ Hydroxyprolin in $1 \mathrm{~m} l$ Serum noch gut erfaßt werden. Die Normalwerte für das Humanserum mit dieser Methode lagen bei $1,58 \pm 0,27(0,86) \mu \mathrm{g} / \mathrm{m} l \mathrm{und}$ für das Hundeserum etwas höher $3,78 \pm 0,45(1,75) \mu \mathrm{g} / \mathrm{ml}$.
\end{abstract}

\section{A simplified method for the determination of free hydroxyproline in serum}

A modified method is presented for the quantitative determination of free hydroxyproline in $1 \mathrm{~m} l$ serum with an analytical error of $4.5 \%$. Blood serum was deproteinized by a complex treatment with absolute ethanol and supercooling. Ethanol-insoluble substances were also eliminated. Thereafter ethanol was removed from the supernatant by vacuum destillation. The free hydroxyproline in the dry residue was determined according to the colorimetric assay. of STEGEMANN and STADLER with certain modifications. Hydroxyproline added to serum was recovered with an error of $2.5 \%$. Quantities of hydroxyproline as low as $0.4-0.5 \mu \mathrm{g} / \mathrm{m} l$ serum were still easily estimated. The mean content of this amino acid in human serum was found to be $1.58 \pm 0.27(0.86) \mu \mathrm{g} / \mathrm{m} l$ and in $\operatorname{dog} \operatorname{serum} 3.78 \pm 0.45(1.75) \mu \mathrm{g} / \mathrm{m} l$.

Die Hydroxyprolinbestimmung in Harn und Serum hat in letzter Zeit bei vielen experimentellen und klinischen Untersuchungen Anwendung gefunden. Es wurden mehrere Angaben bei einer Reihe von physiologischen (1-6) und pathologischen (3,5-15) Zuständen bekannt. Gleichzeitig wurden weitere Verbesserungen und Modifikationen der Bestimmungstechnik vorgeschlagen $(1,9,16-20)$.

Das Hydroxyprolin ist im Organismus der Säugetiere und des Menschen ausschließlich Bestandteil der Skleroproteine des Bindegewebes (Kollagen und Elastin). Dabei beträgt der Hydroxyprolingehalt des Elastin nur $1,8 \%$, so $\mathrm{da} \beta$ die weitaus überwiegende Menge (etwa 14\%) dem Kollagen zuzusprechen ist (21). Infolge dieser Verteilung wird das Hydroxyprolin als Indikator beim Kollagennachweis bzw. bei Stoffwechseluntersuchungen am Kollagen angesprochen.

Die Bestimmung des freien Hydroxyprolin im Serum ist durch zwei Faktoren gekennzeichnet: 1. Geringe Hydroxyprolinkonzentration im Serum und daraus folgend 2. Enteiweißung unter geringer Serumverdünnung bzw. ohne Serumverlust.

Die mitgeteilten Methoden von $\varnothing_{\mathrm{YE}}$ (1) und BaumanN, FrItz und Kallweit (3) können nur als Makroverfahren betrachtet werden, da sie von 4-20 ml Serum ausgehen. Die Enteiweißung nach DüBovskŕ, Pacovský und Dubovská (9) mit Pikrinsäure und anschließender Austauschchromatographie erscheint sehr umständlich und die Mengenangaben sind unvollständig. Die von Laitinen, Nikkilä und Kivirukko (4) vorgenommene Deproteinisierung mit Trichloressigsäure ist im Hinblick auf niedrige Peptide nicht ausreichend und gab bei unseren Nacharbeitungen schwankende Ergebnisse. Morsches, HolzmanN und Schlaudecker (17) fällen das Serumprotein mit Äthanol, um in dem Präzipitat das "Collagen-like-protein" zu bestimmen: StEgEmann und Stalder (18) enteiweißen durch Autoklavieren und anschließende Austauschchromatographie.

Bei kleinerer verfügbarer Menge Blut ergeben sich in allen aufgezählten Fällen Schwierigkeiten bei der Enteiweißung. Entweder erhält man eine zu große Serumverdünnung oder deutliche Verluste nach der Proteinausfällung.

Aus diesem Grund haben wir die folgende Arbeitsmethode entwickelt, der sich die Hydroxyprolinbestimmung nach StegemanN und StadLer (18) in geringer Modifikation anschließt.

\section{Material und Methoden}

\section{Reagenzien}

1. Puffer-Stammlösung, $\mathrm{pH}$ 6: In einem 1-Liter-Meßkolben wurden in etwa $200 \mathrm{~m} l$ destilliertem Wasser der Reihe nach $50 \mathrm{~g}$ Citronensäure (Merck p. a.), $12 \mathrm{ml}$ 96proz. Essigsäure (Merck p. a.), $120 \mathrm{~g}$ Natriumacetat $\times 3 \mathrm{H}_{2} \mathrm{O}$ (Merck p. a.) und $34 \mathrm{~g}$. Natriumhydroxid (Merck p. a.) gelöst und mit destilliertem Wasser bis zur Marke aufgefüllt. Bei $4^{\circ}$ blieb diese Lösung einige Monate stabil.

1a. Puffer für die Chloraminlösung: $500 \mathrm{~m} l$ Stammpuffer $+100 \mathrm{~m} l$ destilliertes Wasser $+150 \mathrm{ml} n$-Propanol. Bei $4^{\circ}$ ist diese Lösung einige Monate haltbar.

1b. Puffer für die Farbreaktion: $100 \mathrm{ml}$ Stammpuffer $+400 \mathrm{ml}$ destilliertes Wasser $+500 \mathrm{ml}$ n-Propanol. Bei $4^{\circ}$ blieb diese Lösung drei Wochen stabil.

2. Chloramin-T-Lösung: 1,41 g Chloramin-T (Merck p. a.) wurden in $10 \mathrm{ml}$ destilliertem Wasser gelöst. Nach Zugabe von $10 \mathrm{ml}$ n-Propanol wuide das Volumen mit Puffer (Reagenz 1a) 
auf $100 \mathrm{ml}$ gebracht. In dunkler Flasche bei $4^{\circ}$ ist das Reagenz einige Wochen stabil.

3. Aldehyd-Perchlorsäure-Reagenz: $15 \mathrm{~g} p$-Dimethylaminobenzaldehyd (Merck p. a.) wurden in $60 \mathrm{ml}$ n-Propanol suspendiert. Anschließend wurden $26 \mathrm{ml}$ 60proz. Perchlorsäure (aus 70proz. Perchlorsäure Merck p. a. hergestellt) hinzugegeben und das Volumen mit n-Propanol auf $100 \mathrm{~m} l$ gebracht. Bei $4^{\circ}$ bleibt das Reagenz eine Woche stabil.

4. Athanol absolut (Merck p. a.).

5. n-Propanol (Merck p. a.).

6. Isoamylalkohol (Schuchardt, München, zur Chromatographie). 7. Standardlösung von Hydroxyprolin: $10 \mathrm{mg}$ vorher getrocknetes Hydroxyprolin (Serva p. a.) wurden in $100 \mathrm{ml} 0,001 \mathrm{~N}$ Salzsäure gelöst. Daraus wurden Standardlösungen mit einem Gehalt von $1,2,5$ und $10 \mu \mathrm{g} / \mathrm{m} l$ hergestellt, indem $1,2,5$ und $10 \mathrm{~m} l$ von der Stammlösung mit $0,001 \mathrm{~N} \mathrm{HCl}$ bis auf $100 \mathrm{ml}$ weiter verdünnt wurden.

\section{Teclonik}

In einem Zentrifugenglas wurden zu $1 \mathrm{ml}$ Serum $5 \mathrm{ml}$ auf $0^{\circ}$ gekühltes absolutes Äthanol zugesetzt. Die Proben wurden 1 Std. bei $-5^{\circ}$ stehen gelassen. Anschließend wurde $10 \mathrm{Min}$. bei 4000 U./Min. in einer vorgekühlten Zentrifuge zentrifugiert. $5 \mathrm{ml}$ Überstand wurden in cin Normalschliffreagenzglas (18 $\times$ $180 \mathrm{~mm}$ ) abpipettiert und nach Zugabe von $0,5 \mathrm{~m} /$ Isoamylalkohol in einem Mikrodestillationsapparat bei $40^{\circ}$ und einem Vakuum von etwa $18 \mathrm{mmHg}$ trocken destilliert.

Der trockene Rückstand wurde in $2 \mathrm{ml}$ Puffer (Reagenz $1 \mathrm{~b}$ ) aufgenommen und die Hydroxyprolinbestimmung nach STEGEMANN und Stalder angeschlossen. Dazu wurden die Proben mit $1 \mathrm{ml}$ Chloramin-T (Reagenz 2) versetzt und bei Raumtemperatur $20 \mathrm{Min}$. stehen gelassen. Anschließend wurde $1 \mathrm{ml}$ Reagenz 3 zugesetzt, kräftig geschüttelt und die Proben wurden in ein Wasserbad bei $60^{\circ}$ gestellt. Nach Ablauf von $15 \mathrm{Min}$. wurden die Gläser mit Leitungswasser rasch abgekühlt und mit $1 \mathrm{~m} / \mathrm{n}$-Propanol versehen.

Die Extinktion wurde innerhalb von $45 \mathrm{Min}$. bei einer Wellenlänge von $550 \mathrm{~nm}$ und einer Schichtdicke von $10 \mathrm{~mm}$ am Spektral-

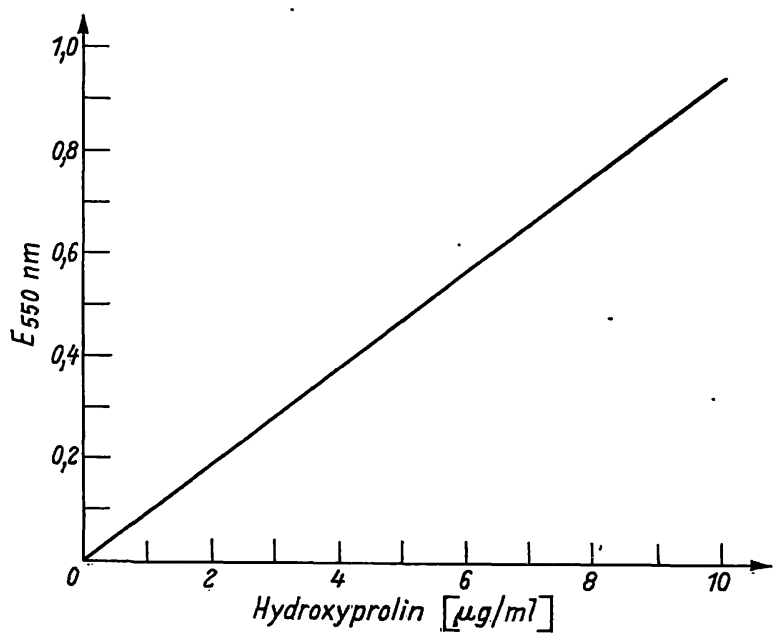

Abb. 1

Eichkurve für die Hydroxyprolinkonzentration von 0 bis $10 \mu \mathrm{g} / \mathrm{m} l$ Serum. Der bei der Enteiweißung entstandene Serumverlust ist berücksichtigt. photometer PMQ II (Zeiss) abgelesen. Die erhaltenen Extinktionswerte wurden mit Hilfe einer Standard-Eichkurve in $\mu \mathrm{g}$ Hydroxyprolin pro $\mathrm{m} l$ Serum umgerechnet (Abb. 1).

\section{Ergebnisse}

Die erhaltenen Extinktionswerte bei verschiedener Wellenlänge (430-610 nm) sind auf Abbildung 2 dargestellt. Daraus ist ersichtlich, daß das Absorptionsmaximum der Farbreaktion für unsere Modifikation im Wellenbereich 550-560 nm liegt.

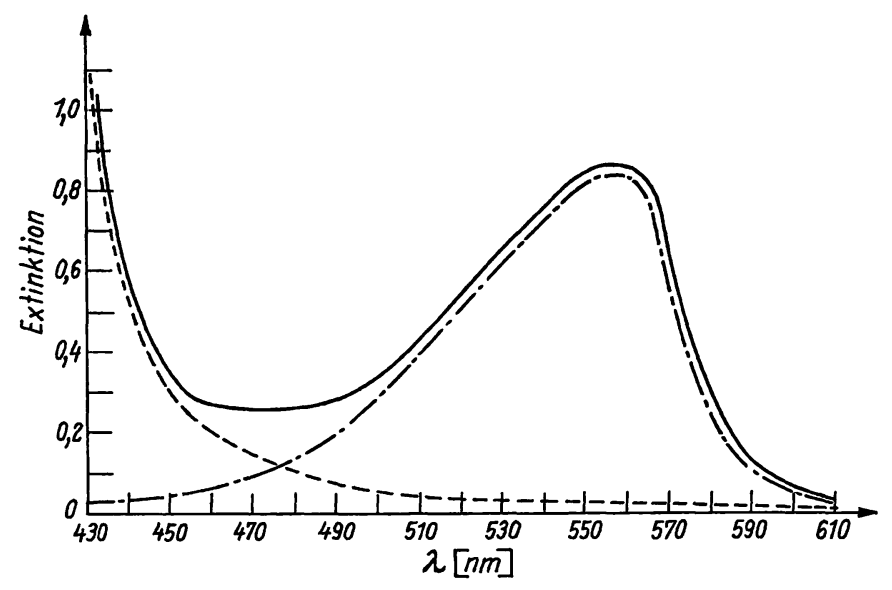

Abb. 2

Absorptionsspektrum des Farbkomplexes bei unserer Modifikation. $-\longrightarrow=$ Probe gegen Leerwert $---1=$ Leerwert gegen Wasser $\underline{ }=$ Probe gegen Wasser

Für den Variationskoeffizient von jeweils 10 parallel durchgeführten Serumbestimmungen des freien $\mathrm{Hy}$ droxyprolin wurde ein Höchstwert von 4,5\% erhalten, der auch als Maximalfehler der beschriebenen Methode anzusprechen ist.

Es wurden Versuche mit Seren bei Hydroxyprolinzugabe durchgeführt, deren Ergebnisse in Tabelle 1 enthalten sind. Das zugesetzte Hydroxyprolin wurde mịt minimalen Differenzen fast vollständig wiedergefunden. Wenn die Unterschiede zwischen dem gefundenen Gesamthydroxyprolingehalt und dem erwarteten Wert nur auf das zugegebene Hydroxyprolin bezogen werden, beträgt der Fehler durchschnittlich 2,5\%.

Die mit dieser Methode erhaltenen Normalwerte für das Humanserum bzw. Hundeserum sind in der folgenden Tabelle 2 dargestellt und zum Teil mit Befunden anderer Autoren verglichen.

\section{Diskussion}

Das Hydroxyprolin ist in absolutem Äthanol nicht löslich. Bei einer Konzentration von etwa $80 \%$, welche bei der von uns vorgenommenen Enteiweißung entsteht,

Tab. 1

Konzentration des freien Hydroxyprolin im Serum vor und nach Zugabe von Hydroxyprolin

\begin{tabular}{|c|c|c|c|c|c|c|c|c|}
\hline \multirow[b]{2}{*}{ Serum } & \multicolumn{2}{|c|}{ Eigener Hydroxyprolingehalt } & \multicolumn{2}{|c|}{ Zugesetztes Hydroxyprolin } & \multicolumn{2}{|c|}{ Gefundener Gesamtgehalt } & \multicolumn{2}{|c|}{ Differenz } \\
\hline & Extinktion & $\mu \mathrm{g} / \mathrm{m} l$ & Extinktion & $\mu \mathrm{g} / \mathrm{ml}$ & Extinktion & $\mu \mathrm{g} / \mathrm{m} l$ & $\mu \mathrm{g} / \mathrm{ml}$ & $\%$ \\
\hline $\begin{array}{l}\text { Patient A } \\
\text { Patient B } \\
\text { Patient C } \\
\text { Patient D }\end{array}$ & $\begin{array}{l}0,167 \\
0,158 \\
0,071 \\
0,091\end{array}$ & $\begin{array}{l}1,74 \\
1,64 \\
0,74 \\
0,95\end{array}$ & $\begin{array}{l}0,035 \\
0,049 \\
0,035 \\
0,075\end{array}$ & $\begin{array}{l}0,36 \\
0,51 \\
0,36 \\
0,78\end{array}$ & $\begin{array}{l}0,200 \\
0,207 \\
0,105 \\
0,165\end{array}$ & $\begin{array}{l}2,08 \\
2,15 \\
1,09 \\
1,72\end{array}$ & $\begin{array}{r}-0,02 \\
0,00 \\
-0,01 \\
-0,01\end{array}$ & $\begin{array}{c}1 \\
0 \\
1 \\
1,4\end{array}$ \\
\hline $\begin{array}{l}\text { Standardserum } \\
\text { Monitrol ,Dade“" }\end{array}$ & 0,169 & 1,76 & 0,041 & 0,43 & 0,212 & 2,21 & $+0,02$ & 1,1 \\
\hline
\end{tabular}


Tab. 2

Serumkonzentration des freien Hydroxyprolin nach verschiedenen Autoren in $\mu \mathrm{g} / \mathrm{m} l$

\begin{tabular}{|c|c|c|c|c|}
\hline Autor & & $\mathbf{n}$ & $\overline{\mathbf{x}} \pm \mathrm{S}_{\overline{\mathbf{x}}}$ & $\mathbf{S}$ \\
\hline ØYE (1) & Humanserum & 10 & $0,92 \pm 0,05$ & 0,17 \\
\hline BAUMANN, Fritz u. Kallweit (3) & Humanserum & 38 & $2,40 \pm 0,02$ & 1,10 \\
\hline LAITINEN, NikKILÄ u. KIVIRIKKo (4) & Humanserum $\left\{\begin{array}{l}18-21 \mathrm{~J} . \\
22-40 \mathrm{~J} \\
41-76 \mathrm{~J} .\end{array}\right.$ & $\begin{array}{l}.38 \\
34 \\
23\end{array}$ & $\begin{array}{l}1,05 \\
1,07 \\
1,01\end{array}$ & $\begin{array}{l}0,77-1,32 \\
0,75-1,51 \\
0,63-1,52\end{array}$ \\
\hline KIVIRIKKo u. Mitarb. (10) & Humanserum & 11 & $1,00 \pm 0,06$ & 0,20 \\
\hline DuBovskÝ u. Mitarb. (13) & Humanserum & 8 & $0,78 \pm 0,11$ & 0,30 \\
\hline STEGEMANN U. STALDER (18) & Plasma & - & 2,6 & - \\
\hline DABEw u. STRUCK & $\begin{array}{c}\text { Humanserum } \\
\text { Hundeserum } \\
\text { Standardserum Monitrol „Dade“ }\end{array}$ & $\begin{array}{r}10 \\
15 \\
4\end{array}$ & $\begin{array}{l}1,58 \pm 0,27 \\
3,78 \pm 0,45 \\
1,73 \pm 0,16\end{array}$ & $\begin{array}{l}0,86 \\
1,73\end{array}$ \\
\hline
\end{tabular}

bleibt das Hydroxyprolin im Überstand gelöst. Parallele Versuche haben keinen Verlust an Hydroxyprolin in unserem Laboratorium ergeben.

Ein wichtiges Moment bei der Enteiweißung ist das sofortige Vermischen des Serums mit dem Äthanol. Infolge der verschiedenen spezifischen Gewichte kann das Serum nach dem Zentrifugieren auf dem Boden des Zentrifugenglases im Niederschlag zum Teil inkludiert bleiben und es so zu ungenauen Ergebnissen kommen. Daher wurde das Äthanol mit einer Vollpipette ausgeblasen und so dem Serum zugesetzt, wobei gleichzeitig eine homogene Mischung entstand.

Bei der Äthanolenteiweißung werden einige Lipidanteile des Serums mitextrahiert, welche später eine Trübung verursachen können. Bei einem normalen Lipidgehalt des zu untersuchenden Serums werden die Lipide in dem Puffer (Reagenz 1b) nach unserer Modifikation gelöst. $\mathrm{Da}$ in der Hälfte der Fälle eine restliche Trübung nach Entwicklung der Farbreaktion die Photometrie infolge eines höheren Lipidgehalts beeinträchtigte, wurde noch einmal Propanol zugesetzt.

Bei der Vakuumdestillation wurde zur Vermeidung eines Siedeverzugs Isoamylalkohol verwendet. Bei langsamer und gleichmäßiger Destillation treten dann keine Verluste durch Verspritzen auf.

Unsere wiederholten Versuche haben eine strenge Linearität der Extinktion als Funktion der Hydroxyprolinkonzentration von $0-10 \mu \mathrm{g} / \mathrm{m} l$ bei der verwendeten Bestimmungstechnik ergeben. Dadurch wird eine ge- naue Berechnung des Hydroxyprolingehalts auch mit Hilfe eines Multiplikationsfaktors ermöglicht. Der letztere ergibt sich aus einem Quotienten der Konzentration zur Extinktion einer Hydroxyprolin-Standardprobe, die parallel mitbestimmt wird. Wie aus Abbildung 1 ersichtlich wurde, können Konzentrationen von $0,4-0,5 \mu \mathrm{g}$ Hydroxyprolin in $1 \mathrm{~m} l$ Serum ohne Schwierigkeiten mit unserer Modifikation noch erfaßt werden. Diese Empfindlichkeit der Methode ist besonders vorteilhaft bei Versuchen an kleineren Tieren, bei denen das verfügbare Untersuchungsmaterial meist gering ist. Utber unsere Erfahrung in dieser Hinsicht wird in einer anderen Publikation später eingegangen.

In Tabelle 2 fallen die großen Differenzen bei der Serumkonzentration des freien Hydroxyprolin zwischen den einzelnen Untersuchern auf. Diese Unterschiede sind auf die verschiedene Enteiweißungsart bzw. anschließende Farbreaktion zurückzuführen. Wir haben mit der angegebenen Enteiweißungstechnik eine kolorimetrische Bestimmung nach Prockop und Udenfriend (22) bzw. Kivirikko, Laitinen und Prockop (11) durchgeführt. Die Extinktionswerte lagen bei gleichen Bedingungen um etwa $30 \%$ niedriger als nach der modifizierten Methode von StegemanN und Stalder. Für die von uns verwendete geringe Menge an Serum reichte diese Empfindlichkeit aber nicht aus.

Wir danken der Kommission der Europäischen Gemeinschaften für die Sachbeihilfe.

\section{Literatur}

1. $\phi_{\mathrm{YE}}, \mathrm{I}$., Scand. J. Clin. Laborat. Invest. 14, 259 (1962). - 2. Keiser, H., E. C. LeRoy, S. Udenfriend und A. SJoerdosma, Science Washington 142, 1678 (1963). - 3. BaumanN, H., E. Fritz und C. Kallwert, Klin. Wschr. 42, 786 (1964). - 4. Laitinen, O., E. A. Nikkirä und K. I. Kivirikko, Acta Med. Scand. 179, 275 (1966). - 5. Dubovsk4, J., J. HRBA und V.PAcovskry, Clin. Chim. Acta Amsterdam 17, 107 (1967). - 6. Brown, H., A. MrLner, J. KenNedy und S. Delena, Metabolism Baltimore 17, 345 (1968). - 7. RebeGNi, M., G. F. Garosi, L. DeI Giovane und G. Ravenni, Atti Accad. fisiocrit. Siena 11, 585 (1962). - 8. Klein, L., F. W. Lafferty, O. H. Pearson und P. H. Curtis, Metabolism Baltimore 13, 272 (1964). - 9. DuBovský, J., V. Pacovský und E. Dubovskí, Clin. Chim. Acta, Amsterdam 12, 230 (1965). - 10. KrvirikKo, K. I., M. KoIvUsalo, O. Laitinen und B. A. Lamberg, J. Clin. Endocr. Springfield 24, 222 (1964). - 11. KivirikKo, K. I., O. LaItinEN und
B. A. Lamberg, J. Clin. Endocr. Springfield 25, 1347 (1965). 12. LeRoy, E. C. und A. S Joerdsma, J. Clin. Invest. 44, 914 (1965). 13. DubovskÝ, J., E. Dubovská, V. PacovskYY und J. Hrba, Clin. Chim. Acta, Amsterdam 19, 387 (1968). - 14. Kalima, T., K. I. Kivirikko, O. Laitinen und J. Uitro, Clin. Chim. Acta, Amsterdam 19, 443 (1968). - 15. Smrtr, R., Clin. Chim. Acta, Amsterdam 23, 421 (1969). - 16. KIVIRIKKo, K. I., O. LAITINEN und D. J. Prockop, Analyt. Biochem. 19, 249 (1967). - 17. Morsches, B., H. HolzmanN und A. SChíaudecker, Ärztl. Forsch., Wörishofen 21, 421 (1967). - 18. StegemanN, H. und K. Stalder, Clin. Chim. Acta, Amsterdam 18, 267 (1967). 19. Dreux C. et J. Leymarie, Ann. Biol. clin. 26, 641 (1968). 20. Woessner, J. F. (Jr.), Arch. Biochem. Biopysics 93, 440 (1961). 21. Chvapid, M., Physiology of connective tissue, S. 235, Czechoslovac Med. Press, Prague (1967). - 22. PRockop, D. J. und S. UDENFRIEND, Analyt. Biochem. 1, 228 (1960).

Priv.-Doz. Dr. H. Struck 5 Köln-Merheim Ostmerheimer Str. 200 